\title{
Determinação de coliformes na água e no tecido mole das ostras extraídas em Cananéia, São Paulo, Brasil
}

\author{
Determination of coliforms in the water and soft tissue \\ of oysters extracted in Cananéia, São Paulo, Brazil
}

\section{Sonia Assami Doi', Ana Julia Fernandes Cardoso de Oliveira², Edison Barbieri ${ }^{3}$}

\section{RESUMO}

Este estudo objetivou avaliar a qualidade microbiológica da água de várias localidades em que são produzidas ostras Crassostrea sp. no estuário de Cananéia, tanto como nos bivalves, por meio dos valores de coliformes baseados na Técnica dos Tubos Múltiplos. Foram realizadas coletas de água em dez localidades durante os anos de 2005 a 2011. A análise da água apresentou média geométrica de coliformes termotolerantes de 24,67 NMP $100 \mathrm{~mL}^{-1}$ e, nos tecidos das ostras, de 15,53 NMP g-1. Verificouse uma diferença significativa entre as localidades analisadas quanto à densidade de coliformes totais e termotolerantes na água. Analisaramse as variações das contagens bacterianas em relação à sazonalidade, verificando-se que o outono apresentou a maior média de coliformes nas ostras, sendo os maiores dados coletados em abril. Houve correlação positiva entre coliformes na água e na ostra.

Palavras-chave: coliformes totais e termotolerantes; estuário; contaminação microbiológica; extração de bivalves.

\begin{abstract}
This study sought to evaluate the microbiological quality of water from the various locations where specimens of the oysters Crassostrea sp. were harvested in Cananéia estuary, as well as of the bivalve itself, through values of coliforms based on the Multiple Tube Technique. During the period from 2005 to 2011, samples of water were collected at ten points. The water analysis presented a geometric mean of thermotolerant coliforms of 24.67 MPN $100 \mathrm{~mL}^{-1}$ and, in the soft tissues of the oysters, of 15.53 MPN g'1. There was a significant difference between the locations analyzed as to the density of total and thermotolerant coliforms in water. After analysis of the variations of bacterial counting with regard to seasonal mean, autumn presented the highest mean numbers of coliforms in oysters, and most data were collected in April. There was a positive correlation between the coliforms found in water and those in the oyster.
\end{abstract}

Keywords: total and thermotolerant coliforms; estuary; microbiology contamination; shellfish harvesting

\section{INTRODUÇÃO}

Os ambientes estuarinos estão sujeitos a diferentes tipos de contaminação, como por veiculação microbiológica pelo lançamento de efluentes domésticos lançados in natura no ambiente, que podem causar riscos à saúde humana e às espécies presentes no hábitat, interferindo na resistência dos bivalves (HENRIQUES et al., 2003; BARBIERI \& DOI, 2011; BARROS \& BARBIERI, 2012; DOI et al., 2012). O estuário de Cananéia é considerado uma das áreas úmidas mais importantes da costa brasileira em termos de biodiversidade e produtividade natural, reconhecido nacional e internacionalmente como o terceiro ecossistema mais produtivo do Atlântico Sul, em função de suas características bem preservadas (UNESCO, 2005). Possui condições propícias para a formação de bancos naturais e para a implantação de engorda e extração da ostra Crassostrea sp., sendo esta região responsável pela maior produção de ostras do Estado de São Paulo (PEREIRA et al., 2003; RISTORI et al., 2007).

Os moluscos bivalves são organismos filtradores que se alimentam das partículas e microalgas que se encontram na água e acumulam, em seus tecidos, grandes quantidades de substâncias orgânicas, inorgânicas, além dos micro-organismos presentes no ambiente, atuando como bioindicador da insalubridade da água (PEREIRA et al., 2006;

\footnotetext{
'Bióloga. Mestre pelo Programa de Pós-Graduação do Instituto de Pesca do Estado de São Paulo vinculado à Agência Paulista de Tecnologia dos Agronegócios (APTA) da Secretaria de Agricultura e Abastecimento (SAA) - São Paulo (SP), Brasil.

²Bióloga. Professora-assistente Doutora da Universidade Estadual Paulista "Júlio de Mesquita Filho" (UNESP), Campus do Litoral Paulista - São Vicente (SP), Brasil.

${ }^{3}$ Oceanógrafo. Mestre e Doutor em Oceanografia Biológica pela Universidade de São Paulo (USP). Professor e Pesquisador do Instituto de Pesca - APTA - SAA/SP - Governo do Estado de São Paulo - Cananéia (SP), Brasil.

Endereço para correspondência: Edison Barbieri - Caixa Postal 157 - Avenida Professor Besnard, s/n - 11990-O00 - Cananéia (SP), Brasil - E-mail: edisonbarbieri@yahoo.com.br Recebido: 28/10/2013 - Aceito: 31/07/2014 - Reg. ABES: 125658
} 
ZANETTE et al., 2006). Nesse sentido, a qualidade microbiológica da água foi monitorada pelos níveis de bactérias indicadoras de contaminação fecal, tais como os coliformes. Este bioindicador se relaciona com o risco potencial de contrair doenças infecciosas por meio de sua utilização para recreação e nos alimentos contaminados (TOURON et al., 2007). O hábito de consumir ostras cruas ou levemente cozidas pode contribuir para o surgimento de diversos casos de doenças transmitidas por alimentos (POTASMAN et al., 2002; MENDES et al., 2004). Assim sendo, é necessário avaliar os contaminantes microbiológicos tanto para a água como para os moluscos frescos.

O grupo dos coliformes é característico dos organismos que crescem no trato gastrintestinal de animais de sangue quente, portanto sua presença no ambiente e nos organismos cultivados indica contaminação fecal (SILVA et al., 2006; CODEX, 2008). O coliforme termotolerante é um dos patógenos amplamente utilizados no monitoramento da qualidade microbiológica da água em que se deseja constatar contaminação fecal recente ou de condições sanitárias insatisfatórias (SILVA et al., 2006).

Em países como os EUA, Chile e Brasil, o cultivo e a extração dos bivalves são controlados pela análise de qualidade da água (SILVA et al., 2006). Entretanto, o nível dos coliformes pode ser afetado por fatores como as correntes, os ventos e a chuva que ocorre na vizinhança do estuário (MIQUELANTE \& KOLM, 2011; DOI et al., 2014).

$\mathrm{Na}$ tentativa de minimizar os problemas relacionados à qualidade sanitária dos moluscos bivalves, alguns programas, tais como o
Programa Nacional de Controle Higiênico Sanitário de Moluscos Bivalves (PNCMB, 2011) e Codex Alimentarius (CODEX, 2008), estabelecem limites permissíveis de contaminação de origem fecal para os moluscos.

Diante da importância da qualidade da água nas áreas de extração da ostra Crassostrea sp. e da contaminação por micro-organismos fecais, este trabalho teve como objetivo comparar a densidade dos coliformes nas águas das áreas de extração com aqueles do tecido mole de tais moluscos bivalves no município de Cananéia, em São Paulo. Os resultados foram avaliados conforme a legislação vigente. A hipótese deste trabalho foi que a densidade de coliformes no tecido da ostra relacione-se diretamente com a contaminação dos coliformes na água.

\section{MATERIAIS E MÉTODOS}

Foram coletadas amostras de águas estuarinas em dez localidades situadas no município de Cananéia (São Paulo), no período de 2005 a 2011, em que se desenvolve a engorda e extração de ostras (Crassostrea sp.), em tabuleiros fixos. As águas foram coletadas mensalmente nas comunidades Agrossolar, Cooperostra, Ilha da Casca, Itapitangui, Mandira, Mosquiteiro, Pedrinhas, Píer, Retiro e Taquari, referenciados por meio do aparelho GPS (global system position). Estes locais foram escolhidos por caracterizarem a estação amostral e pela proximidade dos tabuleiros de engorda (Figura 1). As análises das variáveis ambientais, temperatura $\left({ }^{\circ} \mathrm{C}\right), \mathrm{pH}$, salinidade e oxigênio dissolvido $\left(\mathrm{mg} \mathrm{L}^{-1}\right)$, foram obtidas na própria área da coleta, com o auxílio do equipamento de medição 'Multiparâmetro YSI-63'.

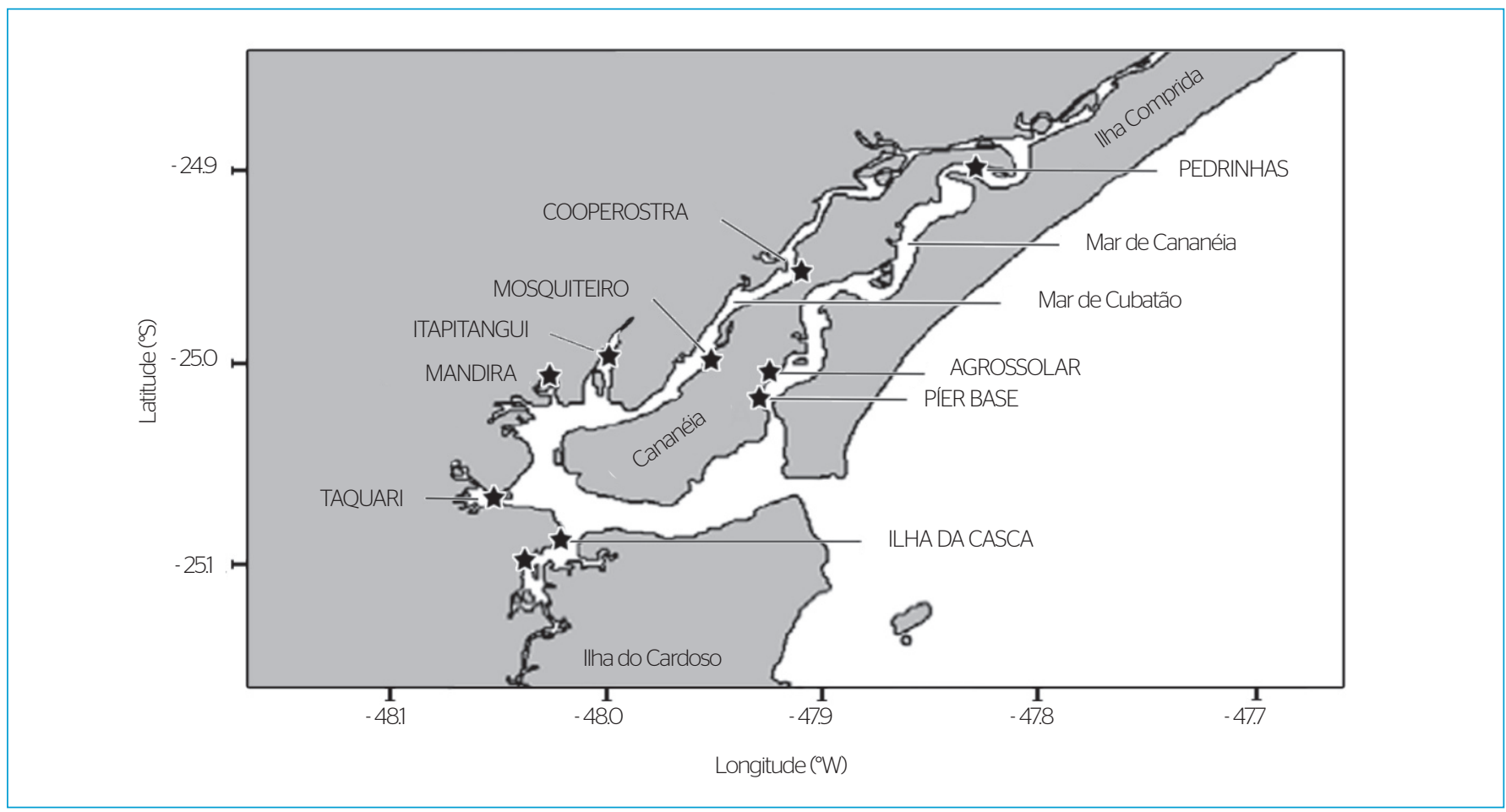

Figura 1 - Localidades em que foram coletadas as águas para análise microbiológica em Cananéia, São Paulo (dez pontos de coleta). 
As amostras de água foram coletadas manualmente, em contracorrente na profundidade de 15 a $30 \mathrm{~cm}$, utilizando-se frascos de vidro neutro de borossilicato. Em seguida, elas foram armazenadas em caixa isotérmica refrigerada para transporte e analisadas dentro de um período máximo de seis horas a partir da amostragem em campo.

Nos mesmos períodos das coletas de águas, as ostras foram adquiridas antes de passarem pelo processo de depuração, na Cooperativa dos Produtores de Ostras de Cananéia (Cooperostra), que consiste em uma cooperativa comunitária possibilitando a organização da comercialização das ostras da região (BARBIERI et al., 2012; MIGNANI et al., 2013)

A avaliação da água e do tecido mole da ostra foi realizada no laboratório do Núcleo Regional de Registro - Consaúde, situado a $50 \mathrm{~km}$ de Cananéia. No laboratório, as amostras foram submetidas à análise para a determinação do número mais provável (NMP) de coliformes totais (Ct) e termotolerantes (CT), baseando-se na Técnica dos Tubos Múltiplos e seguindo a metodologia descrita pelo "Standard Methods for the examination of water and wastewater" (APHA, 2005).

A água foi diluída em água tamponada de proporção 1:9, obtendo diluições decimais seriadas de $10^{-1}$ a $10^{-3}$ (realizadas em duplicatas). Um total de $20 \mathrm{~g}$ do tecido mole da ostra foi recolhido em condições assépticas em recipiente estéril e homogeneizado em $180 \mathrm{~mL}$ de água tamponada. As amostras foram diluídas conforme APHA (2005), contendo Caldo Lauryl sulfato de sódio. Os tubos com amostra da água como da ostra foram incubados em estufa a $35^{\circ} \mathrm{C}$ por 24 a 48 horas. Já aqueles que apresentaram produção de gás nos tubos de Durham e/ou acidificados (coloração amarelada) foram considerados positivos.

Para confirmação dos coliformes totais, os tubos com resultados positivos no teste anterior foram repicados em caldo verde bile brilhante (2\%), incubados a $35 \pm 1^{\circ} \mathrm{C}$ por 48 horas. Para os coliformes termotolerantes, as amostras foram repicadas e incubadas em EC - meio específico para Escherichia coli, utilizado como indicador de bactéria entérica patogênica - por um intervalo de 18 a 24 horas a $44,5 \pm 0,2^{\circ} \mathrm{C}$. Após este período, foram considerados positivos os tubos que apresentaram produção de gás. O resultado das densidades dos coliformes totais e termotolerantes nas águas foi expresso em NMP $100 \mathrm{~mL}^{-1} \mathrm{e}$ NMP g-1 para o tecido da ostra.

Realizou-se o teste estatístico Shapiro-Wilk, em que se observou que a distribuição dos dados não se ajustou à normalidade. Quando a distribuição não foi normal, utilizou-se o teste não paramétrico de Kruskal-Wallis para comparar o nível de contaminação nos diferentes pontos de coleta e para os dados do tecido da ostra analisados, tanto mensalmente quanto sazonalmente. O teste de correlação linear de Spearman verificou a existência de correlação entre os coliformes na água e no tecido da ostra (ZAR, 1999).

\section{RESULTADOS E DISCUSSÃO}

A temperatura da água mensurada neste trabalho variou de 17 a $29^{\circ} \mathrm{C}$ (média de $22,85^{\circ} \mathrm{C}$ ), característica de regiões subtropicais. A salinidade variou entre 0,5 e 27,8; o pH entre 5,89 e 8,26 (média 7,23) e o oxigênio dissolvido (OD) teve média de 5,82 mg.L-1 . A média geométrica geral dos coliformes totais foi de 54,48 e a de termotolerantes de 24,67 NMP $100 \mathrm{~mL}^{-1}$

As águas da região de Cananéia são classificadas como salobra, segundo a resolução do Ministério do Meio Ambiente - Conama no 357 (CONAMA, 2005), por apresentarem salinidade de 0,5 a 30. Essa resolução normatiza, para o cultivo de moluscos bivalves destinados à alimentação humana, pH entre 6,5 e 8,5, OD maior que 5 mg.L.-1 e média geométrica da densidade dos coliformes termotolerantes que não deverá exceder 43 por $100 \mathrm{~mL}$, além do percentil de $90 \%$ não poder ultrapassar 88 coliformes termotolerantes por $100 \mathrm{~mL}$. Os dados ambientais coletados neste trabalho apresentaram valores dentro dos parâmetros definidos por esta resolução para águas salobras de classe 1 , destinadas à conservação ambiental e aquicultura.

Os NMP de coliformes totais e termotolerantes da água variaram de 2 a 1.600 NMP $100 \mathrm{~mL}^{-1}$ nas diferentes áreas de engorda e extração. Mosquiteiro, Píer, Itapitangui e Taquari foram as áreas que apresentaram as maiores médias geométricas de coliformes totais, mas somente Mosquiteiro e Píer mostraram médias elevadas nos termotolerantes (Tabela 1). Apesar de Píer não ser uma área em que se extraiam ostras, utilizou-se como referência (controle) de localidade com contaminação microbiológica.

Valores elevados de coliformes encontrados nestas áreas podem estar sofrendo influência da proximidade da cidade com despejo de efluentes, o que é considerado a principal causa de contaminação das

Tabela 1 - Média geométrica em NMP $100 \mathrm{~mL}^{-1}$ dos coliformes totais e termotolerantes das localidades analisadas, desvio padrão geométrico e porcentagem abaixo de 88 NMP $100 \mathrm{~mL}^{-1}$.

\begin{tabular}{l|c|c|c|c|c|c}
$\begin{array}{l}\text { Locais de } \\
\text { coleta }\end{array}$ & Ct & $\begin{array}{c}\text { DP } \\
\text { (geom.) }\end{array}$ & $\%$ & CT & $\begin{array}{c}\text { DP } \\
\text { (geom.) }\end{array}$ & $\%$ \\
\hline Cooperostra & 47,26 & 4,82 & 64,29 & 25,28 & 4,60 & 74,07 \\
\hline Mosquiteiro & 186,08 & 3,98 & 14,29 & $116,84^{*}$ & 5,66 & 33,33 \\
\hline Itapitangui & 155,95 & 4,51 & 27,27 & 38,20 & 4,76 & 80,00 \\
\hline Mandira & 17,92 & 2,88 & 83,33 & 9,34 & 3,32 & $90,91^{* *}$ \\
\hline Pedrinhas & 11,54 & 2,59 & 100,00 & 5,17 & 2,43 & $100,00^{* *}$ \\
\hline Agrossolar & 38,72 & 5,53 & 78,57 & 19,37 & 7,03 & 84,62 \\
\hline Pier & 331,54 & 4,11 & 16,67 & $125,18^{*}$ & 5,55 & 52,94 \\
\hline Taquari & 100,13 & 4,26 & 54,55 & 26,78 & 4,90 & 78,57 \\
\hline Retiro & 23,27 & 3,11 & 83,33 & 11,36 & 3,01 & $100,00^{* *}$ \\
\hline I. Casca & 17,49 & 2,60 & 92,31 & 11,50 & 2,30 & $100,00^{* *}$ \\
\hline
\end{tabular}

Ct: coliformes totais; CT: coliformes termotolerantes; DP (geom.): desvio padrão geométrico: médias acima dos limites permitidos pela legislação do CONAMA 357/2005; **porcentual dentro do limite da legislação vigente 
águas. A média geométrica geral dos termotolerantes apresentou-se dentro do limite estabelecido, mas somente $78,10 \%$ estavam abaixo do critério estipulado em relação ao percentil, indicando que a água estava com contaminação microbiológica acima da permitida.

As áreas com menores médias colimétricas foram Ilha da Casca, Mandira, Retiro e Pedrinhas, que apresentaram valores de coliformes entre 2 e 130 NMP $100 \mathrm{~mL}^{-1}$ de coliformes totais e de termotolerantes entre 2 e $170 \mathrm{NMP} 100 \mathrm{~mL}^{-1}$, com pouca variação na amplitude entre os dados coletados nas localidades. Verificou-se diferença estatística significativa nas localidades analisadas entre os valores de coliformes totais (Kruskal-Wallis=48,65 e p<0,0001) e os termotolerantes (KruskalWallis=38,68 e p<0,0001). Observou-se diferença estatística entre o nível de contaminação da área mais contaminada (Píer, Mosquiteiro, Itapitangui e Taquari) com aquela que teve menor média de coliformes (Pedrinhas e Ilha da Casca).

Ramos et al. (2010) analisaram amostras de água e ostras quanto à quantidade de coliformes em alguns pontos da Baía Sul da Ilha de Santa Catarina, constatando que houve diferença significativa entre os pontos de coleta, com valores mais elevados em uma região que não permite uma circulação eficiente das águas, o que dificulta a diluição dos dejetos (quando ocorrem os despejos).

A contagem de coliformes totais no tecido da ostra variou de 0,43 a $240 \mathrm{NMP} \mathrm{g}^{-1}$ e dos termotolerantes de 0,24 a $240 \mathrm{NMP} \mathrm{g}^{-1}$, sendo os valores médios de 18,78 e 15,53 $\mathrm{NMP} \mathrm{g}^{-1}$, respectivamente. A resolução vigente da Agência Nacional de Vigilância Sanitária (Anvisa), RDC no 12 de 2 de janeiro de 2001, especifica somente estafilococos coagulantes positivos e de Salmonella sp, mas não oferece critérios para as densidades de coliformes em moluscos in natura (ANVISA, 2001).

O Programa Nacional de Controle Higiênico Sanitário de Moluscos Bivalves (PNCMB, 2011) determinou requisitos mínimos necessários para garantir a inocuidade e qualidade dos moluscos bivalves produzidos no Brasil destinados ao consumo humano, por meio da estimativa da densidade média dos coliformes termotolerantes (em NMP $100 \mathrm{~g}^{-1}$ ). O critério utilizado considera os seguintes valores de coliformes termotolerantes: liberada para consumo $<300 \mathrm{NMP} 100 \mathrm{~g}^{-1}$; liberada sob condição (submeter ao processo de depuração) $\geq 300$ e $\leq 6.000 \mathrm{NMP} 100 \mathrm{~g}^{-1}$; e suspensa quando verificada $>6.000$ NMP $100 \mathrm{~g}^{-1}$. Baseado nos critérios de tal programa, as ostras analisadas apresentam-se "liberadas sob condição", sendo necessário passar pelo processo de depuração a fim de retirar as impurezas em seu interior, antes de serem liberadas para o consumo.

Existem padrões internacionais para determinar os limites de contaminações microbiológicas por meio dos valores de coliformes termotolerantes em tecidos moles das ostras cruas. A "European Union Shellfish Quality Assurance Programme" - EUSQAP (RODGERS, 2001) estabeleceu que estes valores não excedam 6.000 NMP $100 \mathrm{~g}^{-1}$, enquanto que a Codex Alimentarius (CODEX, 2008) determinou como limite $230 \mathrm{NMP} \mathrm{g}^{-1}$ de Escherichia coli, e a "International Commission on Microbiological Specifications for Foods" (ICMSF, 1986) limitou em $16 \mathrm{NMP} \mathrm{g}^{-1}$ de coliformes termotolerantes nos bivalves frescos e congelados. Comparando os dados coletados neste trabalho com as normas internacionais, verificou-se que os coliformes nas ostras estavam inferiores aos recomendados, apresentando-se em condições microbiológicas satisfatórias.

Dados coletados em abril tiveram variações entre 2,6 e $240 \mathrm{NMP} \mathrm{g}^{-1}$, ocasionando um alto desvio padrão. Apesar do citado mês ter apresentado elevados valores de coliformes nas ostras (média de 88,8 $\mathrm{NMP} \mathrm{g}^{-1}$ ), não foram observadas diferenças significativas entre as médias de coliformes totais (Kruskal-Wallis=11,90 e p=0,37) e de termotolerantes (Kruskal-Wallis=14,60 e p=0,20) em relação à análise mensal. O mês de novembro foi o que apresentou a menor média colimétrica, tanto para totais $\left(1,5 \mathrm{NMP} \mathrm{g}^{-1}\right)$ como aos termotolerantes $\left(1,23 \mathrm{NMP} \mathrm{g}^{-1}\right)$, como observa-se na Figura 2.

Verificou-se que as densidades dos coliformes termotolerantes detectados neste trabalho estavam dentro do limite estabelecido pelas instituições citadas, porém constatou-se que, em alguns períodos do ano, os níveis dessas bactérias foram bem elevados. A densidade de micro-organismos nos bivalves filtradores indica o nível de contaminação do momento da coleta, variando de um animal para outro e também depende de condições ambientais, meteorológicas e da atividade geral do organismo (KOLM \& ANDRETTA, 2003; MILL et al., 2006).

As densidades de coliformes encontradas nas ostras foram menores em relação àquelas encontradas na água, corroborando

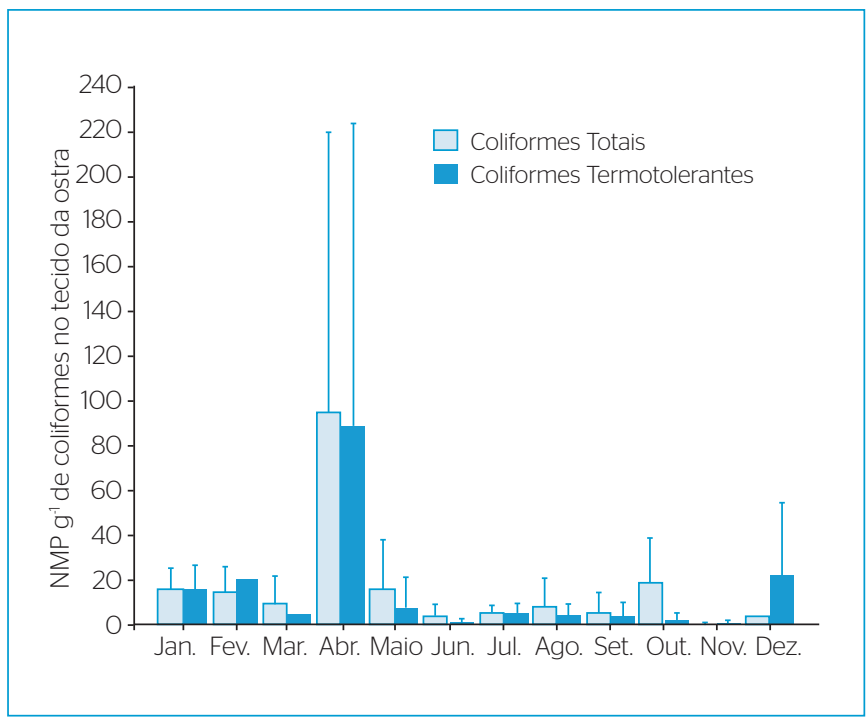

Figura 2 - Médias dos coliformes totais e termotolerantes nos tecidos das ostras (NMP g ${ }^{-1}$ ), analisados mensalmente. As barras apresentam os seus respectivos desvios padrões. 
com o estudo de Vieira et al. (2007) e de Sande et al. (2010), os quais indicaram uma maior contaminação na água do que no molusco. Diferentes resultados foram observados no trabalho de Moreira et al. (2011), realizado em Paraty (Rio de Janeiro), no qual foi descrito que a densidade das bactérias fecais foi mais alta nos moluscos do que na água.

As águas analisadas apresentaram níveis de coliformes elevados no verão $\left(\mathrm{Ct}=213,55\right.$ e $\left.\mathrm{CT}=57,83 \mathrm{NMP} 100 \mathrm{~mL}^{-1}\right)$, divergindo da densidade no tecido das ostras, no qual verificaram-se elevados níveis no outono $\left(\mathrm{Ct}=41,70\right.$ e $\left.\mathrm{CT}=34,08 \mathrm{NMP} \mathrm{g}^{-1}\right)$ em relação ao verão $\left(\mathrm{Ct}=13,07\right.$ e $\left.\mathrm{CT}=15,12 \mathrm{NMP} \mathrm{g}^{-1}\right)$, como visto na Figura 3. Não foi observada diferença estatística nas médias de contaminação no tecido da ostra relacionado à sazonalidade (Kruskal-Wallis de $\mathrm{Ct}=3,90$ e $\mathrm{p}=0,27, \mathrm{CT}=4,49$ e $\mathrm{p}=0,21$ ).

As ostras são consideradas organismos euritérmicos, apresentando faixa de conforto térmico entre 22 a $29^{\circ} \mathrm{C}$ (GALVÃO et al., 2000; CHRISTO, 2006), salinidade recomendada entre o intervalo de 15 a 25 (WAKAMATSU, 1973; PEREIRA et al., 1988; PEREIRA \& CHAGAS SOARES, 1996) e cultivo na zona entremarés é o mais indicado (PEREIRA et al., 2001).

Segundo Imai (1977), esses fatores podem influir direta ou indiretamente no crescimento das ostras, como o $\mathrm{pH}$ abaixo de 6,75, podem reduzir a taxa de filtração de $C$. virginica e, consequentemente, diminuir a captação de alimento. Salinidades inferiores próximas aos níveis de tolerância fazem cessar a alimentação, e a alta concentração de algas pode fazer decrescer ou inibir o estímulo à filtração.

Como as ostras são filtradores e possuem características bioacumuladores, as partículas microbiológicas encontradas na água ficarão retidas

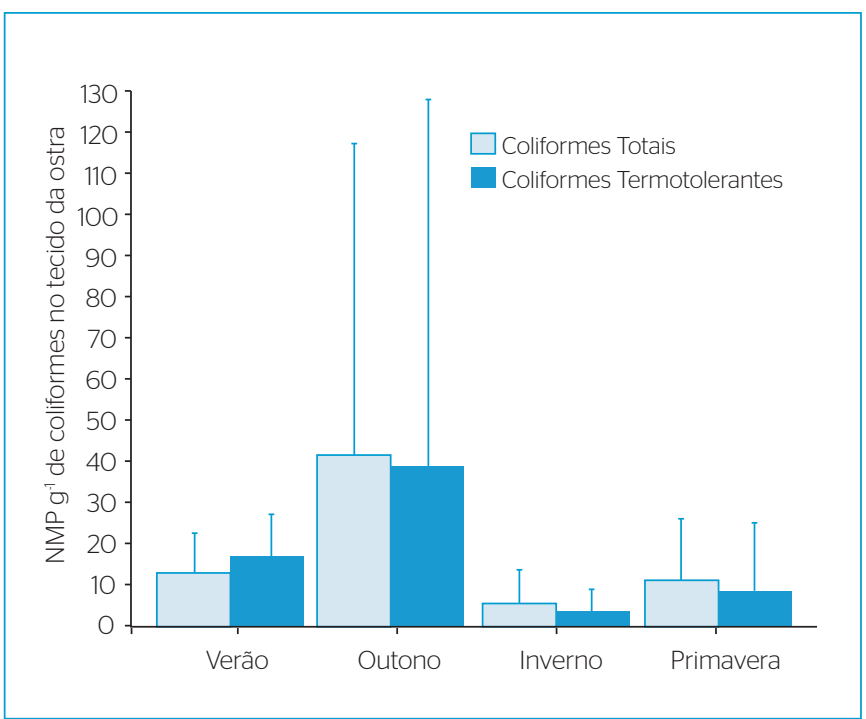

Figura 3 - Valores médios dos coliformes totais e termotolerantes no tecido da ostra (NMP g-1) por estação do ano. As barras apresentam os seus respectivos desvios padrões. dentro do organismo, elevando o nível de contaminação. Resultados semelhantes foram observados por Kolm e Absher (2008), que realizaram o estudo em um complexo estuarino de Paranaguá (Paraná), no qual verificaram que no verão a densidade de coliformes no tecido das ostras foi elevada em relação à água. Farias et al. (2010) e Ramos et al. (2010) notaram que os valores de NMP nas amostras de água e organismo foram mais elevados, principalmente na estação chuvosa. De acordo com Absher (1989), estes organismos se reproduzem no verão, por isso é provável que, para acumular reservas à reprodução, as ostras filtram mais água no verão do que no inverno, retendo mais coliformes em tal época do ano.

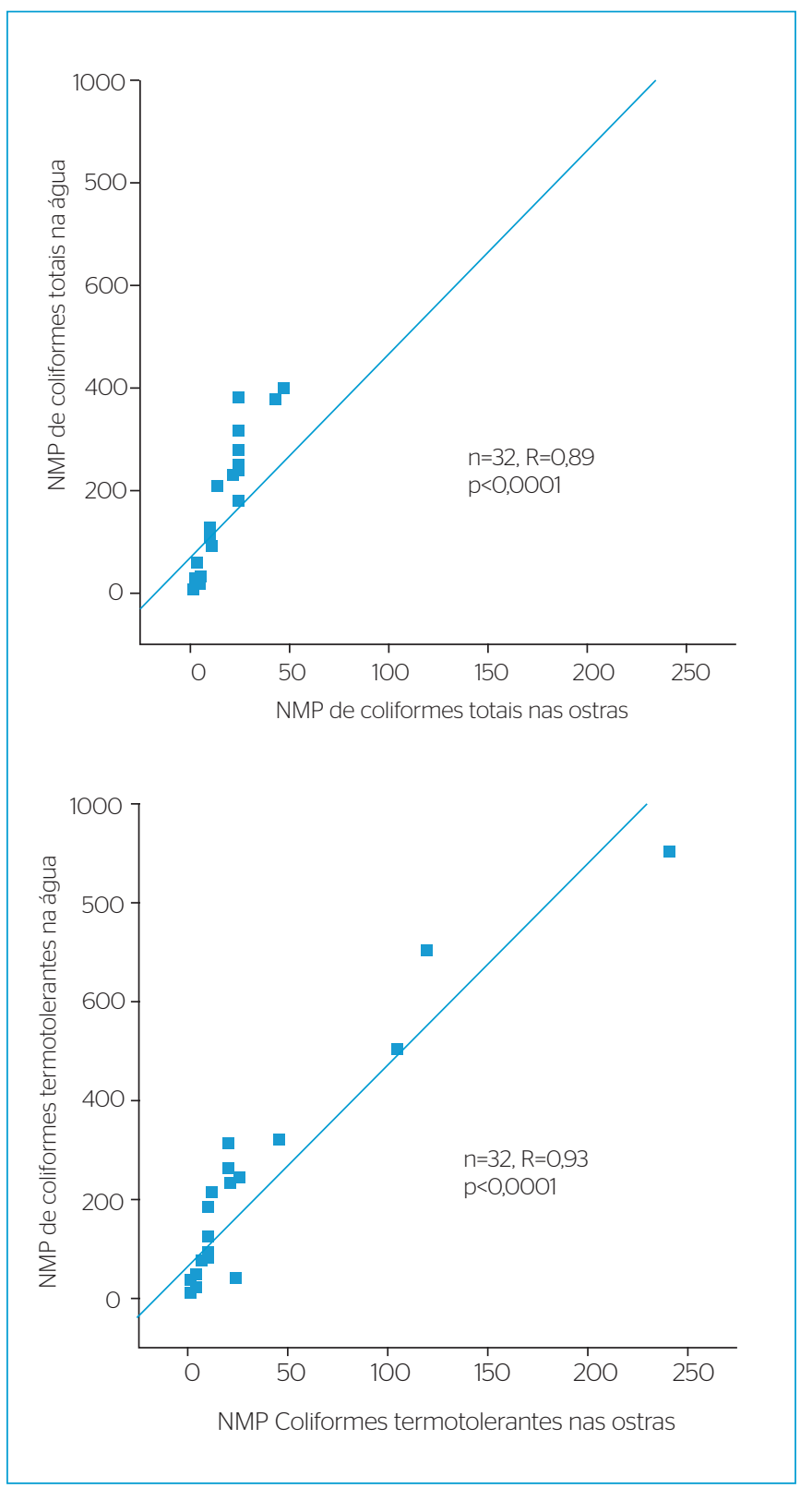

Figura 4 - Regressão linear entre os NMP de coliformes totais e termotolerantes na água e no tecido da ostra $(n=24)$. 
Neste trabalho, constatou-se correlação positiva entre os valores de coliformes totais (Spearman $\mathrm{r}=0,89, \mathrm{p}<0,001$ ) e termotolerantes (Spearman $\mathrm{r}=0,93, \mathrm{p}<0,001$ ) nas águas em relação às ostras (Figura 4). O monitoramento contínuo da qualidade microbiológica da água em que estes organismos são cultivados é necessário, pois representam as condições higiênico-sanitárias daqueles que habitam a região. Resultados divergentes foram descritos por Vieira et al. (2008), os quais verificaram que a contaminação na água no estuário do Rio Pacoti (Ceará) foi maior do que nos bivalves, porém não observaram correlação entre eles.

Os parâmetros de segurança estabelecidos pelas legislações para a produção de bivalves baseiam-se apenas na determinação de coliformes na água, não sendo suficientes para garantir a qualidade microbiológica dos organismos. Além dos coliformes, análise de contaminação por estreptococos está sendo utilizada como um indicador adicional de avaliação da contaminação fecal das águas, por ter característica mais resistente às águas-marinhas (MARTINEZ \& OLIVEIRA, 2010). Quando a análise deste organismo é combinada com os coliformes, o resultado apresenta maior confiabilidade em relação à contaminação fecal.

\section{CONCLUSÕES}

Apesar do valor médio geral de termotolerantes estar dentro do critério da legislação vigente, algumas localidades apresentaram elevadas densidades de coliformes. Entre os dados coletados, somente 78,10\% estavam abaixo do estabelecido, indicando que a água estava fora do limite citado pelo Conama.

Análises do tecido das ostras apresentaram valores médios inferiores às resoluções nacionais e internacionais, mas em algumas épocas do ano, detectaram-se elevados dados de termotolerantes, sendo necessário passar pelo processo de depuração.

As maiores médias de coliformes foram constatadas no verão na água, diferentemente no tecido da ostra, que foi no outono, causado pela característica filtradora e bioacumuladora de partículas em seu organismo.

Houve uma forte correlação das densidades de coliformes entre a água e o tecido da ostra, concluindo-se que a qualidade bacteriológica dos moluscos bivalves refletiu aquela da água analisada, resultado que comprovou nossa hipótese.

\section{AGRADECIMENTOS}

Agradecemos à Fundação de Amparo à Pesquisa do Estado de São Paulo (FAPESP, Processo 2012/50184-8) e ao Conselho Nacional de Desenvolvimento Científico e Tecnológico (CNPq Processo 303920/2013-0 - Bolsa Produtividade) pelo apoio para realização deste trabalho, o qual é dedicado à memória de Gilson Costa Calasans.

\section{REFERÊNCIAS}

ABSHER, T.M. (1989) Populações naturais de ostras do gênero Crassostrea do litoral do Paraná - Desenvo/vimento larval, recrutamento e crescimento. Tese (Doutorado) - Universidade de São Paulo, Instituto Oceanográfico, São Paulo, 185 p.

American Public Health Association (APHA). (2005) Multiple tube fermentation technique for members of the coliform group. In: Standard Methods for the Examination of Water and Wastewater. $2 \mathrm{O}^{\text {th }}$, Washington DC, $1082 \mathrm{p}$

BARBIERI, E.; BONDIOLI, A.C.; WOICIECHOVSKI, E.; ZAPOTOSKI, S.M.K. (2012) Microbiology quality of the oysters cultivation water marketed in Cananéia-SP, Brazil. Mundo da Saúde, São Paulo, v. 36, n. 4 , p. 541-547.

BARBIERI, E. \& DOI, S.A. (2011) The effects of different temperature and salinity levels on the acute toxicity of zinc in the Pink Shrimp. Marine and Freshwater Behavior and Physiology, v. 44, p. 251-263.

BARROS, D. \& BARBIERI, E. (2012) Análise da ocorrência de metais: $\mathrm{Ni}, \mathrm{Zn}, \mathrm{Cu}, \mathrm{Pb}$ e Cd em ostras (Crassostrea brasiliana) e sedimentos coletados no Estuário de Cananéia, SP (Brasil). O Mundo da Saúde, São Paulo, v. 36, n. 4, p. 635-642.
BRASIL. Agência Nacional de Vigilância Sanitária (ANVISA). (2001) Resolução - RDC No 12, de 2 de Janeiro de 2001. Regulamento técnico sobre os padrões microbiológicos para alimentos. Diário Oficial da República Federativa do Brasil, Brasília, DF, 68 p.

BRASIL. Ministério do Meio Ambiente. Conselho Nacional do Meio Ambiente (CONAMA). (2005) Resolução n 357, do dia 17 de março de 2005. Dispõe sobre a classificação dos corpos de água e diretrizes ambientais para seu enquadramento, bem como estabelece as condições e padrões de lançamento de efluentes, e dá outras providencias. Diário Oficial da República Federativa do Brasil, Brasília, DF, p. 208-303.

Codex Alimentarius (CODEX). (2008) Standard for live and raw bivalve molluscus. Codex Standard 292-2008, p. 1-7.

DOI, S.A.; BARBIERI, E.; MARQUES, H.L.A. (2014) Densidade colimétrica das áreas de extrativismo de ostras em relação aos fatores ambientais em Cananéia (SP). Engenharia Sanitária e Ambiental, São Paulo, v. 19, p. 165-171.

DOI, S.A.; COLLAÇO, F.L.; STURARO, L.G.R.; BARBIERI, E. (2O12) Efeito do chumbo em nível de oxigênio e amônia no camarão rosa (Farfantepeneaus paulensis) em relação à salinidade. O Mundo da Saúde, São Paulo, v. 36, n. 4, p. 594-601. 
CHRISTO, S.W. (2006) Biologia reprodutiva e Ecologia de ostras do gênero Crassostrea (Sacco, 1897) na Baía de Guaratuba (Paraná-Brasil): um subsídio ao cultivo. Tese (Doutorado em Zoologia) - Universidade Federal do Paraná, Curitiba. 137 p.

FARIAS, M.F.; ROCHA-BARRERA, C.A.; CARVALHO, F.C.T.; SILVA, C.M.; REIS, E.M.F.; COSTA, R.A.; VIEIRA, R.H.S. (2010) Condições microbiológicas de Tagelus plebeius (Lightfoot, 1786) (Mollusca: Bivalva: Solecurtidae) e da água no estuário do rio Ceará, em Fortaleza - CE. Boletim do Instituto de Pesca, São Paulo, v. 36, n. 2, p. 135-142.

GALVÃO, M.S.N.; PEREIRA, O.M.; MACHADO, I.C.; HENRIQUES, M.B. (2000) Aspectos reprodutivos da ostra Crassostrea brasiliana (Lamarck, 1819) em manguezal do estuário de Cananéia, SP (O250S; 0480W). Boletim do Instituto de Pesca, São Paulo, v. 26, n. 2, p. 147-162.

HENRIQUES, M.B.; MARQUES, H.L.A.; LOMBARDI, J.V.; PEREIRA, O.M.; GARCIA, A.L.B. (2003) Influência da contaminação bacteriológica sobre a resistência do mexilhão Perna perna (Linnaeus, 1758) à exposição ao ar. Arquivos de Ciências do Mar, v. 36, p. 95-99.

IMAI, T. (1977) The Evolution Of The Oyster Culture. In: ROTTERDAM, A.A. Aquaculture in Shallow Sea. Balkema, p. 115-262.

International Commission on Microbiological Specifications for Foods (ICMSF). (1986) Microorganisms in food. Sampling for microbiological analysis: principles and specific applications. 2 ed. Toronto: Blackwell Scientific Publications. 278 p.

KOLM, H.E. \& ABSHER, T.M. (2008) Bacterial density and coliform organisms in waters and oysters of Paranaguá Estuarine Complex, Paraná, Brazil. Boletim do Instituto de Pesca, São Paulo, v. 34, n. 1, p. 49-59.

KOLM, H.E. \& ANDRETTA, L. (2003) Bacterioplancton in different tides of the Perequê tidal creek, Pontal do Sul, Paraná, Brazil. Brazilian Journal of Microbiology, v. 34, p. 97-103.

MARTINEZ, D.I. \& OLIVEIRA, A.J.F.C. (2010) Faecal bacteria in Perna perna (Linnaeus, 1758) (Mollusca: Bivalvia) for biomonitoring coastal Waters and seafood quality. Brazilian Journal of Oceanography, v. 58, n. 8, p. 29-35.

MENDES, E.S.; MENDES, P.P.; LOPES, C.A.M.; COELHO, M.I.S.;SOUZA, J.C.R.; CRUZ, M.C.S.; ASSIS, A.S. (2004) Sazonalidade dos microrganismos em ostras consumidas na grande Recife, PE. Revista Higiene Alimentar, v. 18, n. 116, p. $79-87$.

MIGNANI, L.; BARBIERI, E.; MARQUES, H.L.A.; OLIVEIRA, A.J.F.C. (2O13) Coliform density in oyster culture waters and its relationship with environmental factors. Pesquisa Agropecuária Brasileira, v. 48, p. 833-840.

MILL, A.; SCHLACHER, T.; KAOULI, M. (2006) Tidal and Iongitudinal variation of faecal indicator bacteria in an estuarine creek in southeast Queensland, Austrália. Marine Pollution Bulletin, v. 52, n. 8 , p. 881-891.

MIQUELANTE, F.A. \& KOLM, H.E. (2011) Indicadores microbiológicos de poluição fecal na desembocadura da Gamboa Olho d’Água, Paraná: subsídio para o monitoramento da balneabilidade do Brasil. UEPG Biology Health Science, Ponta Grossa, v. 17, n. 1, p. 21-35.
MOREIRA, A.S.; LEÃO, M.V.P.; SANTOS, S.S.F.; JORGE, A.O.C.; SILVA, C.R.G. (2011) Qualidade sanitária da água e de bivalves Iphigenia brasiliensis (Lamarck, 1818) na praia do Jabaquara, Paraty, RJ. Revista Biociências, UNITAU, v. 17, n. 1, p. 66-71.

PEREIRA, O.M.; AKABOSHI, S; CHAGAS SOARES, F. (1988) Cultivo Experimental de Crassostrea brasiliana (Lamarck, 1819) no Canal de Bertioga, São Paulo, Brasil (23.54.S-45.13.W). Boletim do Instituto de Pesca, São Paulo, v. 15, n. 1, p. 55-65.

PEREIRA, M.A.; NUNES, M.M.; NUERNBERG, L.; SCHULZ, D.; BATISTA, C.R.V. (2006) Microbiological quality of oysters (Crassostrea gigas) produced and commercialized in the coastal region of Florianopolis Brazil. Brazilian Journal of Microbiology, v. 37, n. 2, p. 159-163.

PEREIRA, O.M.; CHAGAS SOARES, F. (1996) Análise da criação de ostra Crassostrea brasiliana (Lamarck, 1819), no sítio Guarapari, na região lagunar-estuarina de Cananéia-SP. Boletim do Instituto de Pesca, São Paulo, v. 23, p. 135-142.

PEREIRA, O.M.; HENRIQUES, M.B.; MACHADO, I.C. (2003) Estimativa da curva de crescimento da ostra Crassostrea brasiliana em bosques de mangue e proposta para a sua extração ordenada no estuário de Cananéia, SP, Brasil. Boletim do Instituto de Pesca, São Paulo, v. 29, n. 1, p. 19-28.

PEREIRA, O.M.; MACHADO, I.M.; HENRIQUES, M.B.; YAMANAKA, N. (2001) Crescimento da ostra Crassostrea brasiliana semeada sobre tabuleiro em diferentes densidades na região Estuarino-Lagunar de Cananéia - SP (250 S, 480 W). Boletim do Instituto de Pesca, São Paulo, v. 27, n. 2, p. 163-174.

Programa Nacional de Controle Higiênico Sanitário de Moluscos Bivalves (PNCMB). (2011) Estabelece os requisitos mínimos necessários para inocuidade e qualidade dos moluscos bivalves destinados ao consumo humano, bem como monitorar e fiscalizar. Instrução Normativa Interministerial, portaria 122. Diário Oficial da União, Brasília, DF, p. 55-58.

POTASMAN, I.; PAZ, A.; ODEH, M. (2OO2) Infectious outbreaks associated with bivalve shellfish consumption: a worldwide perspective. Clinical Infectious Diseases, v. 35, n. 8, p. 921-928.

RAMOS, R.J.; PEREIRA, M.A.; MIOTTO, L.A.; FARIA, L.F.B.; SILVEIRA JUNIOR, N.; VIEIRA, C.R.W. (2O10) Microrganismos indicadores de qualidade higiênico-sanitária em ostras (Crassostrea gigas) e águas salinas de fazendas marinhas localizadas na Baía Sul da Ilha de Santa Catarina, Brasil. Revista do Instituto Adolfo Lutz, v. 69, n. 1, p. 29-37.

RISTORI, C.A.; IARIA, S.T.; GELLI, D.S.; RIVERA, I.N.G. (2007) Pathogenic bacteria associated with oysters (Crassostrea brasiliana) and estuarine water along the south coast of Brazil. International Journal of Environmental Health Research, v. 17, p. 259-269.

RODGERS, C.J. (2001) The NSW Shellfish Quality Assurance Program: an operational review. Sidney: Safe Food Production NSW, 146 p.

SANDE, D.; MELO, T.A.; OLIVEIRA, G.S.A.; BARRETO, L.; TALBOLT, T.; BOEHS, G.; ANDRIOLI, J.B. (2010) Prospecção de moluscos bivalves no estudo da poluição dos rios Cachoeira e Santana em Ilhéus, Bahia, Brasil. Brazilian Journal Veterinary Research Animal Science, v. 47, n. 3 , p. 190-196. 
SILVA, M.P; CAVALLI, D.R.; OLIVEIRA, T.C.R.M. (2006) Avaliação do Padrão de Coliformes a $45^{\circ} \mathrm{C}$ e comparação da eficiência das técnicas dos tubos múltiplos e Petrifilm EC na detecção de coliformes totais e Escherichia coli em alimentos. Ciência e Tecnologia de Alimentos, v. 26, n. 2, p. 352-359.

TOURON, A.; BERTHE, T.; GARGALA, G.; FOURNIER, M.; RATAJCZAK, M.; SERVAIS, P.; PETIT, F. (2007) Assessment of faecal contamination and the relationship between pathogens and faecal bacterial indicators in an estuarine environment (Seine, France). Marine Pollution Bulletin, v. 54, n. 9. p. 1441-1450.

UNITED NATIONS EDUCATIONAL, SCIENTIFIC AND CULTURAL ORGANIZATION (UNESCO). (2005) World Network of Biosphere Reserves - SC/EES - Jumne 2005. The MAB Program. 19 p.

VIEIRA, R.H.S.F.; ATAYDE, M.A.; CARVALHO, E.M.R.; CARVALHO, F.C.T;; FONTELES FILHO, A.A. (2008) Contaminação fecal da ostra Crassostrea rhizophorae e da água de cultivo do estuário do rio
Pacoti (Eusébio, CE): Isolamento e identificação de Escherichia coli e sua susceptibilidade a diferentes antimicrobianos. Brazilian Journal Veterinary Research Animal Science, v. 45, n. 3, p. 180-189.

VIEIRA, R.H.S.F;; VASCONCELOS, R.F.; CARVALHO, E.M.R. (2007) Quantificação de víbrios, de coliformes totais e termotolerantes em ostra nativa Crassostrea rhizophorae, e na água do estuário do Rio Jaguaribe Fortim-CE. Revista Brasileira de Higiene e Sanidade Animal, v. 1, p. 1-13.

WAKAMATSU, T. (1973) A ostra de Cananéia e seu cultivo. São Paulo: SUDELPA, Instituto Oceanográfico, USP, 141 p.

ZANETTE, J.; MONSERRAT, J.M.; BIANCHINI, A. (2006) Biochemical biomarkers in gills of mangrove oyster Crassostrea rhizophorae from three Brazilian estuaries. Comparative Biochemistry and Physiology, Part C: Toxicology \& Pharmacology, v. 143, n. 2, p. 187-195.

ZAR, J.H. (1999) Biostatistical analysis. 4 ed. New Jersey: Prentice-Hall, 663 p. 


\section{Errata}

No artigo Determinação de coliformes na água e no tecido mole das ostras extraídas em Cananéia, São Paulo, Brasil publicado no periódico Revista Engenharia Sanitária e Ambiental, 20(1):111-118.

Na página 111, Onde se lê:

Edson Barbieri

Leia-se:

Edison Barbieri 